\title{
UNA PERSPECTIVA DEL SUR SOBRE CAPITAL GLOBAL, MIGRACIÓN FORZADA Y DESARROLLO ALTERNATIVO
}

\author{
HUMBERTO MÁRQUEZ COVARRUBIAS* \\ RAÚl DELGADO WISE**
}

\section{Resumen}

A partir de las dinámicas del modelo de acumulación y el sistema de poder que configuran la globalización neoliberal y que están en la base de la actual crisis por la que atraviesa la humanidad, en este artículo se analizan las dimensiones críticas de la nueva arquitectura que caracteriza al capitalismo contemporáneo. Frente a la ideología del libre mercado, el argumento refiere que el sistema mundial capitalista está orientado a afianzar el poder del capital monopolista internacional en el ámbito de la producción, finanzas, servicios y comercio, mediante estrategias regresivas como la superexplotación laboral, el rentismo y la depredación de la naturaleza. Esta estrategia posibilita a las grandes corporaciones multinacionales apropiarse de sectores estratégicos y rentables de las economías periféricas y despojarlas del excedente económico y recursos naturales y humanos necesarios para alentar sus propias dinámicas de crecimiento, acumulación y desarrollo. Bajo estas circunstancias, las periferias son reinsertadas a la esfera capitalista mundial reeditando economías de enclave que profundizan las desigualdades sociales y territoriales. Desde una perspectiva del sur, se propone una reconceptualización del desarrollo humano para promover la transformación social vinculada a la equidad, la justicia social y el bien común.

Palabras clave: capital monopolista, crisis civilizatoria, migración forzada, desarrollo humano, seguridad humana.

* Responsable del Programa de Doctorado en Estudios del Desarrollo de la UAZ. Dirección electrónica: hmarquez@estudiosdeldesarrollo.net.

** Director de la Unidad Académica de Estudios del Desarrollo de la UAZ. Dirección electrónica: rdwise@estudiosdeldesarrollo.net. 


\begin{abstract}
Based on the dynamics of the accumulation model and the power system underlying neoliberal globalization and the current crisis faced by humanity, this article analyses the critical dimensions of the new capitalist architecture. Contrary to the free market ideology, we argue that contemporary capitalist is aimed at strengthening the power structure of international monopoly capital in the areas of production, finances, services and trade through regressive strategies, such as labor superexploitation, rentism and the destruction of nature. This strategy enables large multinational corporations to appropriate strategic and profitable segments of peripheral economies and seize economic surplus, as well as natural and human resources that are necessary to promote growth, accumulation and development. Under these circumstances, peripheral countries are reinserted into the world economy reediting enclave economies, and thus exacerbating social and territorial inequalities. From a south-based perspective, we propose a reconceptualization of human development to promote a social transformation process associated with equity, social justice and the common good.
\end{abstract}

Keywords: monopoly capital, civilizing crisis, forced migration, human development, human security. 


\section{INTRODUCCIÓN}

$\mathrm{P}_{\mathrm{d}}$ ara justificar la vigencia de la globalización neoliberal, el pensamiento ortodoxo enuncia varias tesis sobre desarrollo y migración: 1) el desarrollo significa crecimiento económico, competitividad e inversión privada; 2) el programa de reformas neoliberales de ajuste estructural configura el clima ideal para los negocios; 3) la «guerra contra la pobreza» es la nueva política social para contrarrestar la pobreza extrema; 4) la crisis actual es de corto plazo, localizada en el sector financiero, cuya solución proviene de la aplicación de las políticas neoliberales; y 5) existe un vínculo positivo entre migración internacional y desarrollo: la exportación laboral como fuente de desarrollo, los migrantes como integrantes de una comunidad transnacional capaz de establecer relaciones armónicas entre origen y destino, y las remesas como fondo de inversión.

Desde un mirador o perspectiva del sur, en este trabajo postulamos la necesidad de cuestionar a fondo la perspectiva dominante para develar los fundamentos del modelo de acumulación y poder del sistema mundial capitalista, las asimetrías entre centro y periferia, y la diferenciación entre clases y grupos sociales. El propósito es formular un marco conceptual crítico para el estudio del sistema mundial capitalista y las dinámicas de desarrollo desigual que tienen verificativo a nivel espacial y social, así como para la comprensión de las dimensiones de la crisis general del capitalismo neoliberal, en particular, la condición prevaleciente de inseguridad humana y su secuela de migración forzada.

Frente al mito del libre mercado, argumentamos que el sistema mundial capitalista gira en torno de las redes globales del capital monopolista. El gran capital extiende una red de producción, financiamiento, distribución e inversión a nivel mundial que le permite apropiarse de los sectores estratégicos y rentables de las economías periféricas y sustraer el excedente económico generado con múltiples esfuerzos y sacrificios sociales. El proceso de monopolización agudiza los mecanismos de explotación laboral, rentismo y depredación de los ecosistemas a escala planetaria. 
RED GLOBAL DEL CAPITAL

\section{Arquitectura de poder transnacional}

Los países centrales - que en el pasado reciente dominaron vastas regiones del mundo esparcidas en lo que ahora se conoce como países periféricos, subdesarrollados o dependientes - mantienen vigente el control del sistema de poder mundial. El nuevo imperialismo ya no requiere emprender guerras de conquista, aunque ese expediente no se ha abandonado del todo, como sucede en Irak y Afganistán). Ahora basta con el despliegue del poder político, diplomático y militar, además del respaldo de los organismos internacionales - principalmente los financieros - y de las industrias culturales y de entretenimiento. En las periferias, los gobiernos demuestran su aquiescencia cuando adoptan el llamado Consenso de Washington como programa de gobierno, la ideología del libre mercado como justificación política y la democracia liberal como ritual electoral controlado por una reducida élite política al servicio del gran capital.

La alianza de gobiernos centrales —encabezada por Estados Unidos, la Unión Europea (Alemania, Francia e Inglaterra) y Japón- ejerce el control sobre el Fondo Monetario Internacional (FMI), el Banco Mundial (вм) y la Organización Mundial del Comercio (OMC), instancias que operan como instituciones clave en la formulación de programas de gobierno y políticas públicas favorables a los intereses de las Corporaciones Multinacionales (CMN). Asimismo, la coalición militar entre Estados Unidos y la Organización del Tratado del Atlántico Norte (OTAN) despliega un poder supranacional para intervenir en países que, si bien pueden tener regímenes antidemocráticos, aunque otrora eran aliados, disponen de abundantes reservas de recursos naturales, como gas y petróleo.

\section{Égida del capital monopolista internacional}

Las estrategias impulsadas por las grandes CMN, al amparo del entramado de poder transnacional, desencadenan un profundo proceso de reestructuración capitalista que se caracteriza como globalización neoliberal. Este proceso entraña transformaciones en la economía global, 
como el establecimiento de cadenas de subcontratación y comercio intrafirma que las grandes corporaciones extienden como tentáculos a lo largo y ancho de la geografía mundial. La expansión capitalista está dirigida a reinsertar en la economía global los países periféricos que disponen de recursos naturales y humanos abundantes y baratos, mediante la instauración de nuevas plataformas de exportación que operan bajo la modalidad de enclaves. Actualmente, en este tipo de plantas ubicadas en el sur global laboran entre 55 millones (Robinson, 2008) y 66 millones de trabajadores (Singa Boyenge, 2007). En esta red global de capital operan grandes corporaciones manufactureras, financieras, agropecuarias, comerciales y de servicios; no obstante, el capital financiero genera estrategias especulativas que propician la canalización de fondos de inversión, fondos soberanos y excedentes sociales hacia nuevos instrumentos financieros que ofrecen altos márgenes de ganancia en el corto plazo, pero con el riesgo de provocar crisis recurrentes y fraudes masivos que obstruyen y afectan el funcionamiento de la llamada «economía real».

En esencia, el modelo de acumulación mundial está orientado a concentrar poder, capital y riqueza en beneficio de la élite social transnacional que detenta la propiedad de las CMN, el poder de los Estados centrales y el control de los organismos financieros internacionales. A la configuración de redes globales de capital le corresponde una nueva división internacional del trabajo, donde las periferias desmantelan sus propias cadenas productivas y mercados internos para luego fungir como abastecedoras de abundante fuerza de trabajo barata y de recursos naturales, con lo cual se expanden y profundizan los mecanismos de transferencia de excedente y recursos hacia el centro (o los centros), en detrimento de las posibilidades de acumulación y desarrollo de las regiones y países subdesarrollados.

\section{Subsunción del modo de vida y trabajo por el capital monopolista}

Las estrategias implementadas por el proyecto de globalización neoliberal para generar ganancias extraordinarias rompen los cánones tradicionales conferidos a la innovación tecnológica para abarcar formas 
extremas de explotación laboral, mercantilización de la naturaleza, apropiación del trabajo científico-tecnológico y un nuevo papel geoestratégico del Estado.

El mito posmoderno de la difuminación del Estado-nación se derrumba y solamente queda registrado en sus microrrelatos: el Estado constituye la pieza clave para promover los intereses de las CMN. Mientras el Estado central desencadena ofensivas políticas, diplomáticas, militares y culturales para respaldar la configuración de las redes globales de producción, el Estado periférico cambia su orientación para, en lugar de impulsar el mercado interno y la protección social, ensanchar los espacios de valorización del capital monopolista internacional. En este ámbito, no hay evidencia de que los aparatos del Estado dejen de funcionar ya que, por ejemplo, no se desploman sus presupuestos, pero sí el capítulo social para favorecer por múltiples vías las transferencias al sector privado. El papel geoestratégico del Estado es primordial para preservar las asimetrías y desigualdades sociales como factor de atracción de inversiones. El predominio del capital monopolista no puede explicarse sin la injerencia del Estado, pues, además de garantizar la rentabilidad corporativa, controla al sector obrero y deprime sistemáticamente los salarios, amén de que malbarata los recursos naturales y los bienes de la nación.

En los países inmersos en cuadros graves de subdesarrollo y dependencia, donde cunde la degradación social como pauta que niega cualquier pretensión de "cohesión social», subyuga un régimen peligroso de «Estado fallido», caracterizado por la corrupción, criminalidad, inseguridad, antidemocracia e ingobernabilidad. En esas demarcaciones, los vacíos de poder prohíjan la ascendencia de los poderes fácticos, es decir, de aquellos poderes que no rinden cuentas ni son electos por la sociedad, pero que toman decisiones cruciales para el desempeño del gobierno y las instituciones formales. Algunos ejemplos son los grandes medios de comunicación, los grupos empresariales de élite, las jerarquías eclesiásticas, el sector castrense, la milicia y la intelectualidad conservadora.

En casos más extremos, los vacíos de poder y la conflictividad social funcionan como acicates del narcopoder y grupos paramilitares que emprenden ofensivas armadas contra los poderes instituidos, pero también contra la población civil indefensa. Las grandes bandas de narcotráfico 
asumen, a su manera, la faceta de empresa multinacional, que articula un conglomerado empresarial, político y criminal de amplio espectro. La ausencia de contrapoderes o poderes sociales contrahegemónicos facilita el doble papel del Estado como agente monopolista y como fallido promotor del desarrollo social. Esta doble faceta del Estado neoliberal cobra particular fuerza en las periferias, donde opera como eficaz agente del capital monopolista al propiciar un acelerado desmantelamiento del estado de bienestar y generar condiciones óptimas para la apropiación de la naturaleza, la superexplotación laboral y el establecimiento de cadenas de subcontratación y comercio intrafirma vinculadas a la estrategia de internacionalización comandada por las CMN.

Uno de los principales motores del sistema mundial capitalista ha sido el abaratamiento de los costos laborales. Los países subdesarrollados de África, América Latina, Asia y el ex bloque soviético aportan una abundante oferta de trabajo barato que los empleadores y gestores del mercado laboral canalizan hacia segmentos diferenciados y precarización en los planos nacional e internacional. Al no disponer de una organización consolidada en dichos planos, la sobreoferta y movilidad de los trabajadores convierte a la clase obrera en presa fácil de políticas oficiales y encubiertas que promueven la enajenación social y el divisionismo interclasista mediante el establecimiento de jerarquías laborales, nacionales, regionales, raciales y culturales. No es de extrañar que las grandes corporaciones disfruten de enormes paraísos de fuerza de trabajo barata, flexible y desorganizada (Harvey, 2007; Schierup, Hansen y Castles, 2006; Delgado Wise y Márquez, 2009).

Como nunca antes, la biodiversidad, los recursos naturales y los bienes nacionales y comunitarios son apropiados por las grandes corporaciones que aceleran la intensidad productiva como requisito para acrecentar las ganancias, sin reparar en el hecho de que los tiempos y movimientos compulsivos de las grandes inversiones resultan desproporcionados frente a los ritmos de reproducción metabólica de los ecosistemas. La degradación socioambiental aparece como parte del escenario cotidiano de la modernización, una especie de daño colateral que se legitima en la ideología neoliberal, por lo que efectos como la depredación y contaminación de ecosistemas o la detonación 
de hambruna y enfermedades aparecen como postales que, a lo sumo, conmueven a las buenas conciencias y animan acciones filantrópicas. La comunidad científica enciende los focos de alarma y anuncia la aparición de fenómenos como el cambio climático, que se caracteriza por el calentamiento global y la mayor frecuencia e intensidad de eventos climáticos extremos. Los mecanismos de acumulación desenfrenados exorcizan la simbiosis entre sociedad humana y naturaleza (Foladori, 2001; Foster, 1999; Hinkelammer y Mora, 2008; Márquez, 2010a).

La fascinación por el advenimiento de una nueva economía basada en la sociedad del conocimiento - la tecnociencia y la era digital- diluye las diferencias discursivas sobre las desigualdades sociales y territoriales para anunciar la emergencia de un mundo plano enlazado por dispositivos coordinados en tiempo real y apuntalado por supuestos instrumentos financieros creativos. No obstante, el desenvolvimiento de los hechos devela que los avances tecnológicos en informática, telecomunicaciones, biotecnología, nuevos materiales y nanotecnología responden a la exigencia planteada por las grandes CMN de maximizar sus ganancias. Una gran transformación acontece tras bambalinas: el trabajo científico-tecnológico se reorganiza bajo mecanismos como la subcontratación (outsourcing) y la subcontratación en el extranjero (offshore-outsourcing).

Las grandes corporaciones subordinan también a la masa crítica de científicos del sur mediante convenios de colaboración o financiamiento de proyectos de investigación aplicada. La subsunción del trabajo científico-tecnológico transfiere riesgos y responsabilidades de los centros de investigación y desarrollo (cryd) hacia las periferias y permite capitalizar los beneficios mediante la concentración de patentes y la mercantilización de los productos del progreso tecnológico. Tal mercantilización acontece bajo una visión de corto plazo y ajena a toda preocupación social (Freeman, 2005; Lester y Piore, 2004). 


\section{EL EXPEDIENTE DEL DESARROLLO DESIGUAL}

Un rasgo consustancial a la globalización neoliberal es la profundización del desarrollo desigual. La dinámica de acumulación mundial de capital, la división internacional del trabajo, el sistema de poder global y los diversos conflictos de clase extreman la polarización económica, social, política y cultural entre espacios geográficos y clases sociales (Márquez, 2010b). El resultado más conspicuo es la concentración desmesurada de capital, poder y riqueza en manos de una reducida élite $v i s-\grave{a}-v i s$ la degradación permanente de las condiciones de vida y trabajo de la mayoría de la población. Esta contradicción tiene su correlato ${ }^{1}$ en la profundización de las asimetrías entre los principales países centrales o desarrollados y la mayoría de las naciones periféricas o subdesarrolladas. La diferenciación social también tiene registros alarmantes al interior de los países ubicados en ambos polos de la relación.

\section{Transferencia sistemática de excedente y recursos}

Una conjunción de viejos y nuevos mecanismos de extracción/transferencia de excedente y recursos agudiza la diferenciación espacial y social en diversos ámbitos y niveles: 1) en las periferias, derivado del imperialismo económico y político que sobrepone los intereses metropolitanos; 2) entre países desarrollados y subdesarrollados o entre estos últimos, como resultado de esquemas de integración regional asimétrica; y 3) en el ámbito intranacional, a consecuencia de políticas excluyentes de desarrollo nacional. La transferencia de ganancias y recursos se realiza mediante mecanismos como el pago de deuda externa e interna, los subsidios públicos a las CMN, la apropiación de los frutos del progreso tecnológico, la financiarización y el extractivismo de recursos naturales.

En el marco de la llamada «ayuda para el desarrollo» y los programas de ajuste estructural, los organismos financieros internacionales, como el FMI y el BM, así como los grandes bancos privados internacionales

\footnotetext{
${ }^{1}$ Existen, no obstante, importantes excepciones, como la gestión estatal del desarrollo en países que guardan distancia de los preceptos neoliberales o que impulsan proyectos contrahegemónicos, particularmente en el sudeste asiático y Sudamérica.
} 
con sede en los países centrales - habitualmente aquellos que ejercían dominio colonial en el pasado o que ahora detentan el papel de hegemón-imponen esquemas crediticios a los gobiernos de los países subdesarrollados. En la mayoría de los casos, las deudas externa e interna se han multiplicado y comprometen a los estados a transferir divisas y sacrificar partidas del gasto público orientadas al desarrollo social y la inversión en infraestructura básica.

Los gobiernos locales y nacionales de los países periféricos canalizan porciones significativas de recursos presupuestales para facilitar el arribo de inversión extranjera, con lo cual se subsidia la inversión inicial mediante la dotación de infraestructura, donación de terrenos y naves industriales, el pago de salarios de obreros en etapas de entrenamiento, otorgamiento de exenciones fiscales y la provisión de múltiples servicios públicos. Asimismo, bajo los esquemas de inversión pública-privada, los gobiernos otorgan concesiones preferenciales al capital monopolista internacional, con el respaldo de los recursos públicos, para que emprendan nuevos desarrollos turísticos, inmobiliarios, industriales, comerciales y de servicios.

El capital monopolista internacional reestructura los sistemas de innovación a nivel mundial mediante el control de patentes y productos del progreso tecnológico y el empleo de trabajadores científico-tecnológicos en las periferias para abaratar costos y disminuir riesgos y para acceder, en última instancia, a fuentes de ganancia extraordinaria. No solamente eso, sino que, al subsumir el trabajo de científicos y tecnólogos del sur global, reorienta la capacidad de innovación de esos ámbitos para fortalecer el posicionamiento hegemónico de las CMN y profundizar el subdesarrollo y la dependencia del mundo periférico.

El capital financiero, una fracción preponderante del capital monopolista internacional, implementa estrategias especulativas propias de un capital ficticio, a fin de generar con facilidad ganancias en el corto plazo, lo cual obra en contra del desempeño de la llamada economía real y desemboca en fraudes masivos y crisis recurrentes. La alta volatilidad y los juegos especulativos también aceleran la depuración de capitales, que termina por beneficiar la concentración y centralización del capital monopolista, en tanto que propicia fenómenos lacerantes 
como desempleo, hambruna y pauperización. En este juego perverso incursionan no solamente los grandes capitales y ahorros del primer mundo, sino que también se comprometen recursos financieros del tercer mundo, como fondos soberanos, presupuestos públicos, fondos de pensiones y fondos de inversión; estos recursos se desvían de la actividad productiva o la promoción del desarrollo social para entrar en la economía-casino mundial.

Los recursos naturales como petróleo, minerales, gas, maderas y agua son saqueados indiscriminadamente por las CMN que instalan economías de enclave en zonas con alto contenido de biodiversidad o provisión de riquezas del subsuelo para extraerlas en grandes cantidades en el menor tiempo posible, empleando fuerza de trabajo local que es remunerada con bajos salarios y que tiene predestinado el desempleo, apenas se agoten los suministros estratégicos de recursos naturales. Estas formas de sobreexplotación de la naturaleza arrojan como saldo la contaminación ambiental, la destrucción de ecosistemas, enfermedades y desempleo (Vega, 2006).

\section{Emergencia de nuevas modalidades de intercambio desigual}

Desde la óptica de la teoría estructuralista de la Comisión Económica para América Latina (Cepal) ${ }^{2}$ y las teorías de la dependencia, ${ }^{3}$ el concepto de intercambio desigual tenía centralidad para explicar la dinámica del desarrollo desigual en el horizonte centro-periferia; no obstante, los análisis contemporáneos sobre el capitalismo mundial

\footnotetext{
${ }^{2}$ La hipótesis de Prebisch-Singer sobre el deterioro de los términos de intercambio, introducida a principios de la década de 1950, es fundamental para del pensamiento cepalino (Prebisch, 1986); también los trabajos de Celso Furtado tuvieron una fuerte influencia en esta perspectiva (Mallorquín, 2007; Bresser-Pereira, 2007).

${ }^{3}$ Más allá de los acalorados debates que en el ámbito del marxismo se suscitaron en las décadas de 1970 y 1980 (Samir Amin et al., 1971; Shaikh, 1979; Florian, 1979; Valenzuela, 1979; Chatelain, 1979), no cabe duda que los escritos pioneros de Emmanuel (1973) - publicados originalmente en 1969- sobre el intercambio desigual influyeron a los teóricos de la dependencia. Empero, como es de suponer, las numerosas variantes del análisis de la dependencia y el trabajo teórico sobre el intercambio desigual ofrecen perspectivas analíticas que requieren un mayor desarrollo y adecuación a las realidades del capitalismo contemporáneo (Brewer, 1980: 208-32; Munck, 2000).
} 
omiten su consideración. El concepto de intercambio desigual resulta crucial para develar la transferencia de excedentes implícita en las redes globales de capital y sus mecanismos de interconexión.

El debate clásico sobre el intercambio desigual estuvo circunscrito a la división internacional del trabajo que confiere a la periferia el papel de proveedor de materias primas y al centro el de suministrador de productos industrializados. Esta división continúa vigente para un número significativo de países periféricos; no obstante, algunos países periféricos de reciente industrialización, principalmente de la región asiática, fungen también como proveedores de bienes industrializados, incluso con componentes de alta tecnología. ${ }^{4} \mathrm{~A}$ la modalidad tradicional de intercambio desigual se agrega una nueva, que cobra progresiva centralidad y define los contornos de una nueva división internacional del trabajo: la exportación de fuerza de trabajo. La nueva modalidad implica un intercambio mucho más desfavorable para la periferia que el referido al patrón de intercambio de materias primas por bienes manufacturados. La exportación de fuerza de trabajo dispone de dos mecanismos complementarios, uno indirecto y otro directo.

\section{1) Exportación indirecta de fuerza de trabajo}

La configuración de redes globales de capital desmantela las cadenas de producción en las periferias, las cuales terminan por desempeñar el pobre papel de apéndices productivos de las CMN, pues implica trasladar al exterior prácticamente la totalidad del excedente económico generado. Una gran masa de obreros de la agricultura, industria, los servicios y el comercio trabaja ahora bajo ese andamiaje de intercambio desigual. La subordinación productiva de la periferia reedita la lógica del enclave exportador e inhibe cualquier perspectiva autónoma de acumulación y desarrollo.

\footnotetext{
${ }^{4}$ En escritos posteriores a su famosa hipótesis elaborada junto con Prebisch sobre el deterioro de los términos de intercambio, Singer (1975) prevé situaciones de esta naturaleza al ir más allá del simple análisis de la evolución de los precios relativos entre dos clases de mercancías, para considerar la problemática de estructuras de producción diferentes entre centro y periferia, al poner el acento en el progreso técnico.
} 
El aprovisionamiento de insumos importados se realiza a través de operaciones en el extranjero o mediante contratos de maquila o ensamble exentos de impuestos - o incluso subsidiados- y libres de toda responsabilidad en materia de derechos laborales y ambientales.

El principal contenido de origen nacional de las mercancías de exportación es el trabajo vivo invertido en su producción; el sustrato del auge exportador de materias primas y manufacturas de las periferias está compuesto por el valor de la fuerza de trabajo, generalmente barata.

La reorientación socioeconómica de la periferia hacia el entramado productivo, comercial y financiero orquestado por las CMN propicia que las regiones y países involucrados promuevan una camada de empleos -tanto para el proletariado tradicional (agricultura e industria), como para el nuevo proletariado (servicios y comercio) - sometida a un régimen de inseguridad y sobreexplotación: bajas remuneraciones, alta intensidad laboral, prolongadas jornadas, riesgos, accidentes y expectativa permanente de desempleo. Al final de cuentas, las CMN explotan, sin cortapisas, fuentes abundantes de trabajo barato en las periferias y abaratan significativamente los costos de producción (Delgado Wise y Márquez, 2007a; Márquez, 2007; Cypher y Delgado Wise, 2010).

En los hechos, la contribución efectiva del capital foráneo al proceso de acumulación regional y nacional se limita a una exigua derrama salarial, merced a los enormes diferenciales salariales, y, en el mejor de los casos, a un reducido impacto multiplicador por la vía del consumo. En última instancia, la exportación indirecta de fuerza de trabajo conlleva una transferencia neta de las ganancias al exterior.

Un cambio cualitativo relativamente reciente en la exportación indirecta de fuerza de trabajo es la creación de complejos científico-tecnológicos en las periferias como parte de la estrategia de reestructuración de los sistemas de innovación a nivel mundial. Estos complejos, que funcionan bajo esquemas de subcontratación, transfieren al exterior bienes intangibles que tienen un valor y un significado estratégico aún mayor que las ganancias netas provenientes de las maquiladoras y demás plantas de ensamble. Nos referimos a la transferencia de capacidades para el desarrollo y progreso, que redunda en ventajas competitivas y ganancias extraordinarias para los agentes que controlan el proceso, en este caso las CMN. 


\section{2) Exportación directa de fuerza de trabajo}

La exportación directa de fuerza de trabajo vía migración laboral significa la transferencia de beneficios futuros que se anticipan como ahorros en los gastos de formación y reproducción social de la fuerza de trabajo migrante. Como se ha demostrado para el caso de México, principal país exportador de migrantes del mundo, estos costos no son compensados por el flujo de remesas (Márquez, 2007; Delgado Wise, Márquez y Rodríguez, 2009).

Para países periféricos con una avanzada transición demográfica, la exportación de trabajadores entraña la transferencia del bono demográfico, es decir, de la población en edad productiva y reproductiva que sirve de soporte para el sostenimiento de los dependientes económicos, principalmente niños y adultos mayores. En un sentido más profundo, esta transferencia implica la pérdida del recurso más importante para la generación de riqueza en el país de origen: su fuerza laboral. Más todavía, la exportación de fuerza de trabajo altamente calificada exacerba el problema, al reducir seriamente las capacidades nacionales de innovación y la implementación de proyectos de desarrollo con basamento tecnológico. El punto crítico es que franjas importantes del trabajo en I+D también se están transfiriendo con la emigración de científicos y tecnólogos.

El desplazamiento de población excedentaria o supernumeraria de la periferia hacia regiones desarrolladas permite no solamente cubrir déficits estructurales en la demanda laboral - derivados del envejecimiento poblacional y la insuficiente oferta laboral—, sino que tiende a incrementar la competencia por puestos de trabajo en diversos sectores de la economía de destino y a presionar a la baja los niveles salariales del conjunto de la clase trabajadora. Más que un simple juego de oferta y demanda, como pregonan los artífices del modelo neoliberal, este proceso se inscribe en las estrategias del capital monopolista internacional ${ }^{5}$

\footnotetext{
${ }^{5}$ Un claro ejemplo de esto es la reestructuración del sector manufacturero en Estados Unidos que, a través de operaciones de ensamble o maquila y comercio intrafirma, ha trasladado al exterior partes significativas del proceso productivo. Ello ha traído consigo un severo impacto en el empleo doméstico, que se manifiesta en la pérdida de casi cuatro millones de puestos de trabajo en el sector entre 1994 y 2008. Aunado a esta medida, que permite a las corporaciones gozar de paraísos de fuerza de trabajo barata en el exterior,
} 
para superexplotar la fuerza de trabajo de las periferias con un costo invaluable para los países y regiones de origen.

La movilidad humana inherente a la expansión global del capital conjuga una maraña de flujos migratorios internos e internacionales que responden a las dinámicas del capital, en especial a la nueva división nacional e internacional de trabajo. En el trasfondo, las migraciones configuran una modalidad significativa de transferencia de recursos económicos y humanos en beneficio del gran capital, dinámica que se asocia a la acumulación por despojo y a la emergencia de formas de superexplotación del trabajo inmediato y del control del trabajo científico-tecnológico.

\section{VIOLENCIAS SISTÉMICAS E INSEGURIDAD HUMANA}

La Declaración Universal de los Derechos Humanos de la Organización de las Naciones Unidas (ONU), que promulga el compromiso de los países miembros para preservar los derechos fundamentales de la humanidad, ha sido conculcada por las dinámicas económicas y políticas de la globalización neoliberal. El discurso globalista descansa en la ideología del libre mercado, el fin de la historia, la democracia electoral y el combate al terrorismo. Sin embargo, en la práctica, promueve los intereses de las grandes corporaciones y promulga un pensamiento único, nulificando alternativas. Mientras que el discurso enaltece el concepto de ciudadanía y los derechos y oportunidades de los ciudadanos en el marco de una economía abierta, la participación política se reduce a la emisión del voto en respuesta a una oferta electoral diseñada por un sistema político excluyente. Simultáneamente, los derechos humanos fundamentales tienden a ser socavados y supeditados a la doctrina de seguridad nacional y a las exigencias de una economía de mercado al servicio de los intereses del capital monopolista internacional.

se ha impulsado simultáneamente un proceso de reemplazo de trabajadores nativos por fuerza de trabajo inmigrante a la que, como es el caso de la mexicana, se le confieren salarios que se reducen, en promedio, a la mitad del que reciben los nativos (Delgado Wise, Márquez y Rodríguez, 2009). 
La acumulación mundial de capital y el sistema de poder global conjugan una serie de violencias sistémicas que prohíjan una condición social de inseguridad humana que agrede y vulnera, sobre todo, a los sectores sociales despojados, excluidos y necesitados. Desde el poder político del Estado y el poder económico del gran capital se emprende el desmantelamiento del sistema social de subsistencia, destacadamente del modo de vida y trabajo campesino que, más que una economía rural, es un complejo entramado socioproductivo que provee de alimentos a la población en general y de medios de subsistencia a las comunidades agrarias, además de que la cultura rural funge como basamento para la preservación de ecosistemas y formas de convivencia social.

Un dato sintomático de las luchas del capital contra el trabajo es la prolongada y extensa guerra contra el trabajo vivo; el ataque sistemático en contra de los trabajadores, sus organizaciones autónomas, prestaciones y condiciones de vida es uno de los ejes primordiales del neoliberalismo. Las que pudieran considerarse como conquistas históricas de los trabajadores, como la legislación laboral, el salario social, el salario remunerativo y la protección estatal, se desmantelan; en su lugar, se impone un régimen de inseguridad laboral y superexplotación que legitima el despido libre, el incremento e intensidad de la jornada laboral y la disminución salarial. Conforme a estimaciones de la Organización Internacional del Trabajo (ОIт), el número de trabajadores en condiciones de inseguridad laboral ascendió, en 2009, a 1,530 millones - abarcando poco más de la mitad de la masa laboral mundial-; 630 millones obtuvieron un ingreso salarial menor a 1.25 dólares por día, es decir, se ubicaron en situación de pobreza extrema, y el número global de desempleados fue de 205 millones (OIT, 2011).

El régimen de estado de bienestar (o social) también se desarticula. La red de protección social en materia de salud, educación, vivienda, empleo, alimentación, además de los servicios públicos como abasto de agua potable, recolección de basura, construcción de infraestructura, transporte público, es desincorporada del Estado para cederlo, de manera tajante o gradual, al capital privado y saciar así su sed de ganancia.

La soberanía alimentaria de las periferias y los pueblos pobres es vulnerada por el proyecto neoliberal. El nuevo orden agroalimentario 
mundial, comandado por las grandes agroindustrias, controla la producción y distribución de alimentos y somete a estas mercancías a mecanismos especulativos de corte bursátil y financiero que encarece el precio de los comestibles y repercute en la restricción al acceso que tienen los pobres a alimentos sanos, nutritivos y suficientes que les permitan garantizar tanto la supervivencia como la reproducción de las energías vitales del trabajo vivo.

Los sujetos despojados, excluidos y marginados son reducidos por el sistema de poder y acumulación a su condición de mercancía humana, a una forma corporal de trabajo vivo cada vez más sobreexplotado. Las dinámicas estructurales, políticas e institucionales vulneran sistemáticamente las condiciones de vida y de trabajo, mientras que las instituciones pretenden suavizar los estragos con políticas asistencialistas otorgando dádivas o paliativos para los pobres extremos. Dicha política ha sido nombrada como "guerra contra la pobreza».

Derivada de las estrategias imperiales globales, se implementa la guerra contra el terrorismo, el crimen organizado y la inseguridad. En los países periféricos como Rusia, Colombia, México, Afganistán, Italia, El Congo y demás, el crimen común y el organizado generan una espiral de violencia que atenta contra la ciudadanía inerme, merced a vacíos de poder e, incluso, colusión del poder político y empresarial. Las acciones delictivas se diversifican: desde narcotráfico, tráfico de personas, trata de personas, tráfico de órganos, piratería, fraude cibernético, extorsión, secuestro y tortura, entre otros. Se forman asociaciones de bandas criminales con grupos empresariales, políticos y policiacos para controlar una fuente de riqueza, que entraña una fuerte dosis de violencia. Las mafias del poder prohíjan conglomerados empresariales, financieros y políticos que articulan actividades ilícitas altamente lucrativas y que actúan bajo un velo de impunidad y corrupción. Con ese pretexto, los gobiernos con talante autoritario militarizan la sociedad, en parte para intimidar a los sectores rebeldes y opositores y en parte para propagar el miedo entre los sectores medios, desinformados y fácilmente atemorizados. Esta estrategia no atenta, sin embargo, contra el corazón financiero del crimen organizado; está orientada, en cambio, a promover el respaldo de algunos sectores de 
la ciudadanía al incremento de medidas coercitivas y punitivas que terminan por reforzar la violencia del Estado y la criminalización de los sectores más vulnerables. Las bandas criminales reclutan a jóvenes sin perspectiva de futuro para que jueguen el papel de carne de cañón, es decir, sicarios o pistoleros que, movidos por el dinero fácil, están dispuestos a matar o morir. La criminalización de los excluidos, pobres y necesitados acontece por todas las vías - gubernamental y criminal—, y se complementa con tácticas fascistas de aniquilación de grupos rebeldes mediante la activación de grupos paramilitares o escuadrones de la muerte que imponen la ley de los poderes fácticos en territorios bajo su dominio y estrategias homicidas de limpieza social, que pretende exterminar a los pobres de la calle porque, a ojos de los potentados, afean la ciudad.

Las violencias y políticas guerreristas contra los sectores más vulnerables de la sociedad no suelen aparecer en el primer plano, pero forman parte de la urdimbre que teje la estrategia de expansión y dominio promovida por el capital monopolista internacional y los poderes globales. Asimismo, están imbricadas con las diversas expresiones de inseguridad humana que acompañan a las migraciones contemporáneas.

\section{MIGRACIONES FORZADAS A LA SOMBRA DE LA NUEVA DIVISIÓN INTERNACIONAL DEL TRABAJO}

Durante la globalización neoliberal, las migraciones adquieren un nuevo papel dentro de la división del trabajo. Los mecanismos del desarrollo desigual generan condiciones estructurales, como el desempleo y la pobreza, que catapultan las migraciones masivas de conjuntos poblacionales despojados y excluidos. Compelidos por la necesidad de acceder a medios de subsistencia u oportunidades de movilidad social, vastos sectores de la población son literalmente expulsados de sus territorios para desplazarse dentro del propio país o hacia el extranjero. ${ }^{6}$ La sobreoferta

\footnotetext{
${ }^{6}$ En esta perspectiva, resulta importante reconceptualizar la migración forzada en sentido amplio y contrarrestar las políticas de migración que apelan a la soberanía y seguridad nacional para criminalizar al migrante e infringir sus derechos. Muchos de
} 
laboral y el creciente deterioro de las condiciones de vida confieren a las migraciones, en particular a las provenientes de países periféricos, el carácter de migración forzada (Delgado Wise, Márquez y Puentes, 2010; Márquez, 2010b). ${ }^{7}$

Las migraciones forzadas tienen tres características en común: a) se verifican en los planos nacional e internacional, preponderantemente desde las regiones deprimidas de las periferias con destino a regiones relativamente más avanzadas de las periferias o los centros; b) afectan primordialmente a los sectores vulnerables, pobres y excluidos que no disponen de basamentos materiales y subjetivos para garantizar la supervivencia o alimentar una expectativa de vida decorosa; $c$ ) generan una sobreoferta de trabajo barato y desorganizado que es aprovechada por empleadores y corporaciones interesadas en abaratar costos; $\mathrm{y} d$ ) alimentan los mecanismo de exportación directa e indirecta de fuerza de trabajo, poco calificado y de alta calificación.

El monto de migrantes - provenientes en su mayoría de las periferias - ha crecido ostensiblemente en las últimas tres décadas y media, al pasar de 84 millones, en 1975, a 215 millones, en 2010. Los principales flujos siguen la dirección sur-norte (82 millones) y sur-sur (74 millones), además de un significativo contingente de migraciones internas (750 millones) que, en conjunto, reconfiguran el mapa laboral y convierten a la migración en una pieza clave del proceso de reestructuración capitalista (ONU, 2004, 2006 y 2010; Delgado Wise y Márquez, 2007 b y 2009). Las migraciones registradas en el horizonte sur-sur,

los programas de trabajadores temporales son un buen ejemplo de esquemas aparentemente humanizados que, sin embargo, ocultan explotación y violación a los derechos humanos. Otros ámbitos importantes de discusión son la migración irregular, la trata y el tráfico de personas, la discriminación, la racialización y la violencia de género; la seguridad de defensores de los derechos humanos; los estándares laborales y la agenda de trabajo decente; los instrumentos internacionales de protección de derechos, así como la progresividad y no regresión de los derechos como obligación de los Estados.

${ }^{7}$ Desde la óptica de los derechos humanos, este término es empleado para referirse básicamente a un núcleo específico de migrantes: los exiliados, refugiados o desplazados; en menor medida, se hace extensivo a los llamados migrantes económicos (Castles, 2003; Gzesh, 2008). Para quienes enarbolan la visión dominante, el grueso de los migrantes no tiene cabida en esta noción, puesto que asumen que se trata de movimientos poblacionales voluntarios y libres. 
incluyendo la migración de tránsito y la intranacional, afrontan las condiciones de mayor vulnerabilidad y ocupan los escalafones más bajos en las dinámicas de desplazamiento que generan los procesos de acumulación por despojo. El flujo de remesas de dinero remitidas por los migrantes del norte hacia el sur se ha venido incrementando a un ritmo mayor, al elevarse de 57 mil millones de dólares, en 1995, a 325 mil millones de dólares, en 2010 (BM, 2010). Haciendo abstracción de la condición social de las remesas - una fracción del salario precario percibido en el país de destino-, organismos internacionales como el вм у el Banco Interamericano de Desarrollo (BID), ofuscan la realidad $\mathrm{y}$ consideran estos fondos pecuniarios como una fuente inagotable de recursos para el desarrollo de los países expulsores de migrantes. Este fabuloso mito o «nuevo mantra del desarrollo» (Kapur, 2004) tergiversa la realidad y enmascara la emergencia de nuevas formas de intercambio desigual.

\section{TIPOLOGÍA DE LA MIGRACIÓN FORZADA}

La migración forzada interna e internacional caracteriza al grueso de los movimientos poblacionales bajo el capitalismo neoliberal. La matriz propulsora de las migraciones está compuesta por las violencias estructurales, políticas e institucionales y la condición de inseguridad humana que aqueja a los pobres y excluidos de la tierra. Según sus causas, los principales tipos de migración forzada son los siguientes:

1. Catástrofes o cambios ambientales. Fenómenos naturales como inundaciones, sequías, terremotos y huracanes pueden tener un poder destructivo de tal magnitud que destruyen poblados o zonas habitacionales, además de la infraestructura natural necesaria para la producción. La degradación ambiental y la contaminación derivada de la producción desenfrenada y la expansión de la mancha urbana, que destruyen los hábitats, agreden la biodiversidad y limitan el acceso a recursos naturales para los pobres. Además, los fenómenos asociados al cambio climático y el calentamiento global constituyen, junto con los otros elementos, una fuente recurrente o emergente, según co- 
rresponda, para detonar las migraciones forzadas. Por las políticas de apoyo internacional, la asistencia a los migrantes se denomina «refugio» (Castles, 2002). ${ }^{8}$

2. Conflictos sociopolíticos y culturales. Las desigualdades sociales, las fricciones intergrupales y las controversias políticas abonan a la conflictividad social que empuja a familias, grupos y sectores sociales a abandonar sus lugares de origen. La violencia desatada por estos desequilibrios puede provenir del Estado, guerrillas, paramilitares o ejércitos invasores. El conflicto es un reflejo de la frágil gobernabilidad y de la pérdida de legitimidad de las instituciones y modelos de desarrollo. Algunas modalidades de este tipo migratorio están reconocidas en el derecho internacional bajo el rubro de asilo, refugio y desplazamiento, aunque no siempre los instrumentos protectores son asequibles para los afectados. El número actual de refugiados y asilados se estima en 15 millones (ONU, 2009).

3. Criminalidad y narcotráfico. Las bandas del crimen organizado, que irrumpen en lugares donde el Estado propicia vacíos de poder, agreden a la población civil mediante acciones como asalto, extorsión, secuestro, trata de personas, violación, tortura y asesinato. La violencia desatada confronta a las fuerzas policiacas y militares contra las bandas criminales y grupos paramilitares, y termina por enturbiar la convivencialidad y desmadejar el tejido social, amén de que despoja a las familias de su patrimonio, desarticula las familias, genera paranoia y psicosis y deteriora la presencia de las instituciones. Ante el escenario de descomposición social, la población se ve obligada a emigrar para salvar la vida o mantener una cierta tranquilidad personal y familiar.

4. Tráfico y trata de personas. La trata de personas está asociada a coerción, rapto o engaño, e incluye la explotación sexual y la adopción

\footnotetext{
${ }^{8}$ La consideración de los migrantes por causas ambientales requiere, sin embargo, eludir las especulaciones numéricas (Myers y Kent, 1995; Shuaizhang et al., 2010; Lonergan y Swain, 1999; Black, 2001) y no trivializar los impactos negativos de los cambios ambientales. El punto crítico es descifrar la vulnerabilidad y, en su caso, la capacidad de adaptación de las poblaciones más pobres ante las contingencias ambientales, tanto naturales como antropogénicas (McAdam, 2010).
} 
ilícita, entre otras graves violaciones a los derechos humanos. ${ }^{9}$ En los últimos años, esta forma de migración forzada se ha incrementado en forma alarmante y convertido en un negocio altamente lucrativo, debido a las políticas restrictivas de los países receptores y a las difíciles condiciones de vida en los países periféricos.

5. Despojo de medios de producción y subsistencia. El proyecto neoliberal reclama la apertura de amplios espacios de valorización para el gran capital; los sectores de subsistencia se consideran un lastre y un ámbito apetecible para la privatización y mercantilización de sus recursos naturales y fuerza de trabajo. Los gobiernos emprenden feroces programas de ajuste estructural que tienen el cometido de desarticular estos sistemas de producción, como las llamadas economía campesina, economía social y economía popular, lo cual incluye la expropiación de territorios y bienes comunes para la realización de grandes obras de infraestructura, urbanización y asentamiento de CMN, que despoja a amplios sectores sociales de sus medios de producción y subsistencia. Paradójicamente, en muchos casos, las poblaciones despojadas terminan trabajando como asalariados de las grandes corporaciones en sus propios territorios o se ven compelidos a emigrar.

6. Exclusión social, desempleo estructural y pobreza. La tendencia a la monopolización y extranjerización de las economías nacionales contraen cambios estructurales que desarticulan y desmantelan los sistemas productivos, financieros, comerciales y de servicios, obligando a enormes grupos poblacionales a emigrar en búsqueda de una fuente de sustento familiar. El grueso de la población padece exclusión social en su condición de productor, trabajador, consumidor y ciudadano (Osorio, 2010). El desempleo estructural caracteriza a los sectores

\footnotetext{
${ }^{9}$ Los términos «trata de seres humanos» $\mathrm{y}$ «tráfico ilícito de migrantes» han sido erróneamente usados como sinónimos, por esa razón frecuentemente se incluye esta categoría en alguna de las otras aquí mencionadas. La respuesta mundial frente al crecimiento de esta forma de criminalidad fue la Convención contra la Delincuencia Organizada Transnacional firmada en Palermo, en 2000. También existe el Protocolo para Prevenir, Reprimir y Sancionar la Trata de Personas, Especialmente Mujeres y Niños, que son los más vulnerables. Se considera que existen al menos 2.45 millones de personas que desempeñan trabajo forzoso como consecuencia de la trata interna o internacional de seres humanos (OIM, 2008).
} 
sociales subalternos, por lo que el capital puede maniobrar con facilidad para ajustar a la baja los salarios y deteriorar otras condiciones de trabajo. La pobreza cubre a la mayoría de la población; para superarla, se renuevan los motivos para emigrar hacia zonas urbanas o con mayor dinamismo económico en el país o el extranjero. El despojo, la exclusión, el desempleo y la pobreza generan los mayores flujos migratorios laborales contemporáneos que caen en esta categoría, cuyo sello es la vulnerabilidad y explotación extrema.

7. Sobrecalificación laboral relativa. Los sectores laborales de alta calificación -académicos, investigadores, intelectuales, artistas, científicos, tecnólogos, ingenieros y profesionistas - conforman una masa crítica para el desarrollo nacional, pues son los generadores del conocimiento y la cultura que podrían aplicarse para el bien común. No obstante, las periferias disponen de mercados laborales precarios, apoyos institucionales limitados, infraestructura deficiente, remuneraciones bajas, por lo que una porción importante de estos trabajadores resulta, paradójicamente, una población redundante, con un grado de sobrecalificación relativa que no puede aprovecharse en los lugares de origen. La carencia de oportunidades, los debilitados sistemas de innovación, la segmentación del mercado laboral y el limitado respaldo institucional propician que muchos trabajadores de alta calificación no encuentren en su propio país o lugar de origen una ocupación acorde a sus capacidades y formaciones. Si bien estos migrantes no afrontan grandes problemas para desplazarse ni buscan satisfacer sus necesidades más elementales, recurren a la migración como opción para realizar sus potencialidades laborales e intelectuales no obstante padecer, en muchas ocasiones, de degradación laboral y discriminación salarial en los lugares de destino.

El tipo 1 de migración forzada se refiere a la vulnerabilidad de asentamientos humanos y conjuntos familiares ante la embestida de los fenómenos naturales o las vicisitudes del cambio climático, toda vez que no existe una infraestructura pública y natural que brinde seguridad a los pobladores. El tipo 2 alude al estallido social en los ámbitos local, regional y nacional entre grupos sociales, fuerzas policiales y militares 
que se disputan el control territorial y el predominio de ideologías, proyectos o intereses. Los tipos 3 y 4 expresan grados extremos de degradación social o Estado fallido, puesto que en diversos ámbitos territoriales los grupos armados del crimen organizado y paramilitares pretenden imponer su dominación a costa de la convivencialidad y tranquilidad de la población civil. Los tipos 5, 6 y 7 se refieren a los desajustes en los modos de vida y trabajo derivados de la penetración de las grandes CMN, la imposición de las políticas neoliberales y los desencantos de la democracia electoral.

\section{Violación de derechos humanos de los migrantes forzosos}

Las condiciones en que se desenvuelven las migraciones forzadas conllevan múltiples riesgos y peligros a lo largo del periplo migratorio - particularmente para los grupos más vulnerables-, incluyendo su exposición permanente a condiciones de precarización laboral y exclusión social en los lugares de destino. Más aún, como se indicó antes, la migración internacional está siendo crecientemente sometida a políticas y prácticas de criminalización, racialización y discriminación por raza y género, que no solamente incrementan la vulnerabilidad y riesgos, sino que muchas veces ponen en peligro la vida misma (Delgado Wise y Márquez, 2009; Castles y Delgado Wise, 2008).

El respeto a los derechos humanos sigue siendo una asignatura pendiente para la mayoría de los gobiernos de los países de origen, tránsito y destino; pocos países están eximidos de esta responsabilidad. En los principales países de destino, bajo el estigma de la ilegalidad o por prejuicios raciales, pero sobre todo por intereses económicos, hay un desconocimiento tácito de los derechos laborales y humanos de la población migrante y una obstrucción a los derechos de residencia legal y ciudadanía. Por su parte, en los países de origen y tránsito prevalece un doble discurso: al tiempo que los gobiernos denuncian las violaciones a los derechos de sus connacionales en el destino, se violan derechos de extranjeros en el territorio propio y se ignora que muchos de quienes migran lo hacen porque son literalmente forzados a abandonar el país o 
lugar de origen ante la ausencia de políticas de desarrollo y oportunidades de empleo digno. ${ }^{10}$

La migración internacional, aun cuando dispone de ciertos medios de protección - como los contemplados en la Convención Internacional sobre la Protección de los Derechos de todos los Trabajadores Migratorios y sus Familias de 1990, no ratificada aún por ninguno de los países receptores importantes-carece de mecanismos para su efectiva implementación. En vez de tipificar adecuadamente la problemática a la que están expuestos, se les ubica en la categoría de migrantes económicos, en un entorno que presupone la existencia de libertad individual, movilidad social y libre mercado.

La nueva migración laboral es sometida a condiciones de explotación extrema; bajo el principio de «seguridad nacional», los migrantes son sometidos a condiciones de criminalización, explotación, vulnerabilidad y exclusión social (Delgado Wise, Márquez y Puentes, 2010).

\section{CRISIS GENERAL DEL CAPITALISMO MONOPOLISTA}

A finales de la primera década del presente siglo estalló una crisis general del capitalismo mundial con epicentro en Estados Unidos, que se desempeña como el hegemón mundial. La mayoría de los diagnósticos proponen un relato reduccionista: es una crisis de corto plazo, circunscrita a la órbita financiera, que deviene de la especulación y codicia desbordadas. La solución es sencilla: rescate de grandes capitales, regulación de mercados financieros y aplicación de más políticas neoliberales.

El problema es más complejo: la crisis del capitalismo contemporáneo afecta múltiples dimensiones del sistema mundial y representa una vorágine destructora de capital, población, naturaleza, infraestructura, cultura y conocimiento; empero, esta crisis no solamente

\footnotetext{
${ }^{10}$ En el marco de la migración forzada, es preciso reconocer que las mujeres constituyen un grupo de alta vulnerabilidad, en particular cuando se ven obligadas a cruzar la frontera por canales irregulares. Pese a que la extensión y vulnerabilidad de la migración femenina ha sido crecientemente reconocida, no ha corrido con la misma suerte el diseño de políticas migratorias con perspectiva de género (Jolly, 2005).
} 
expresa una fractura del sistema financiero conectada al problema de sobreproducción, sino que significa una crisis del modelo civilizatorio que pone en predicamento la vida humana en distintos ámbitos del planeta y anuncia una fractura en el proceso del metabolismo sociedad-naturaleza (Márquez, 2009 y 2010c). Algunas pautas del quiebre civilizatorio son las siguientes:

- Rupturas en el proceso de valorización del capital global. La caída general de la tasa de ganancia precipita una fractura en los procesos de financiamiento, producción, distribución y consumo. El exceso de capital en la economía global, que no encuentra condiciones para su realización en el ámbito productivo, debido a la caída de los márgenes de ganancia y el declive de la demanda efectiva, principalmente por la contención de salarios e ingresos del grueso de la población, genera una acentuada crisis de sobreproducción (Bello, 2006). Concomitantemente, la expansión especulativa del capital financiero, en su modalidad ficticia, genera una fuente de ganancia extraordinaria, pero también desencadena burbujas especulativas cuya eclosión afecta el tejido socioeconómico, atasca el funcionamiento de la economía real y desemboca en una depresión de la economía global (Foster y Magdof, 2009). La transferencia del excedente social a la órbita de la especulación representa una perversión rentable de la inversión capitalista. A trasmano de la depresión de la economía mundial, el quiebre de empresas genera una destrucción y depuración de capitales que, al final de cuentas, permite una concentración del capital, valga decir, una mayor acumulación de poder de las grandes CMN que, paradójicamente, no escapan a las dinámicas disruptivas que aquejan al sistema capitalista en su conjunto.

- Degradación de la condición social de la mayoría de la humanidad. La expansión territorial del capital global exige el abaratamiento extremo del trabajo como requisito para su radicación. Además, los procesos de innovación tecnológica convierten en prescindible a grandes masas de trabajadores; en tanto, las grandes corporaciones implementan programas de despidos y esquemas de subcontratación para depurar sus estructuras de costos. Aún más, la depresión económica 
arroja amplios contingentes de trabajadores a las calles. En suma, los trabajadores son considerados como un recurso desechable. En tanto, el nuevo orden agroalimentario mundial, que arrasa con los sistemas de subsistencia social, como el modo de vida campesino, desemboca en episodios recurrentes de carestía y hambruna para los más pobres del planeta. Enormes masas de población pobre no disponen de recursos necesarios para cubrir la necesidad primaria, la alimentación. Las grandes corporaciones agroindustriales especulan con los precios, insumos y nuevas tecnologías - por ejemplo, transgénicos- a costillas de la ruina de campesinos pobres y sin tierra. La mancha de la pobreza cubre a enormes franjas de poblaciones en el mundo. Los excluidos ven limitado su acceso a recursos productivos, financieros, tecnológicos y educativos, pero también a fuentes de empleo y medios de subsistencia; padecen enfermedades y muertes que pudieran prevenirse. En tal sentido, la vida humana de millones de personas está realmente amenazada en el planeta. De esta manera, la exclusión socioeconómica de amplios contingentes poblacionales, en calidad de productores y consumidores, genera una expulsión de personas en busca de sustento en el extranjero; el despoblamiento de localidades es una postal trágica del problema. La entrada de remesas es un espejismo, puesto que reanima el ingreso familiar, pero en un contexto de deterioro social drástico. Las crecientes desigualdades sociales, el desmantelamiento del estado de bienestar y la descomposición del sistema de subsistencia acentúan los problemas de pobreza, desempleo, violencia, inseguridad y precariedad laboral, todo lo cual ejerce una presión para migrar.

- Fractura del proceso metabólico entre sociedad y naturaleza. La degradación de los recursos naturales, el cambio climático y la mercantilización del ecosistema contribuyen a la destrucción de la naturaleza que se manifiesta como una fractura estructural de las bases materiales para la producción y la reproducción de la vida humana (Hinkelammert y Mora, 2008). La crisis generalizada cuestiona el estilo de globalización imperante y, en un sentido más profundo, el orden sistémico global, que devasta las principales fuentes de riqueza - el trabajo y la naturaleza-, las cuales han sido a tal punto sobreexplotadas 
y deterioradas que ponen en riesgo el entramado civilizatorio mismo. Adquieren gran visibilidad problemas como la pérdida de biodiversidad y de especies animales y vegetales, la erosión de terrenos de cultivo, la deforestación y la contaminación, a lo que se suman otros que han adquirido gran difusión, como el cambio climático y el calentamiento global. Sin embargo, persisten problemas estructurales más severos, como el intercambio ecológico desigual, que deja contaminación, pobreza, abandono y destrucción en territorios que son saqueados, bajo una lógica extractivista, por las grandes CMN.

- Regresión de la política y la cultura. Sobre el modelo neoliberal y su clase política postulante se cierne la deslegitimación, en tanto que asistimos a la entronización de los poderes fácticos y las coaliciones turbias de los partidos de derechas e izquierdas. En contrapartida, se promueve la despolitización de la sociedad, la destrucción de sujetos sociales colectivos en beneficio de un ciudadano mínimo, individualista, egoísta y conservador. El saldo es contrastante, por una parte, la sensación de desánimo y apatía y, por la otra, expresiones de resistencia y rebelión. La imposición del pensamiento único, neoliberal, afianza marcos analíticos con una manifiesta incapacidad para entender el presente. La importación inmisericorde de teorías y conceptos es un recurso a la moda que, no obstante, inviste de prestigio autoral. El pensamiento crítico es olvidado o motejado como anquilosado. La imposición de patrones de consumo, formas de pensar, de vestir y actuar carcome los procesos de socialización y produce identidades individualistas y consumistas. El influjo de la industria del entretenimiento, encabezada por el cine de Hollywood y la televisión comercial, aunado a la degradación inducida del sistema educativo, prohíjan una ciudadanía precaria.

- Acumulación de poder plutocrático e insustentabilidad social. La globalización neoliberal conjuga un modelo de acumulación mundial (capital monopolista) y un sistema de poder cuyo cometido es concentrar el capital y la riqueza en una reducida élite, sin tomar en cuenta los múltiples costos ambientales y sociales. Los multimillonarios han incrementado de manera inconmensurable sus fortunas y dominios; incluso la crisis ha servido de oportunidad para depurar capitales y afianzar el poder de las plutocracias. En contraste, se produce un sensible achicamiento de 
las clases medias; pero, sobre todo, los sectores excluidos, despojados y marginados son compelidos a sobrevivir en condiciones cada vez más severas, al grado de que los sectores de pobreza extrema consideran improbable vivir una buena vida; más aún, afrontan severos problemas de desempleo, hambre, pobreza, violencia y muerte. Factores como la sobreoferta de trabajo barato en el mundo, la configuración de redes globales de capital y la innovación científico-tecnológica acrecientan la capacidad de producción de mercancías de todo tipo; sin embargo, la capacidad de consumo de la mayoría de la población se debilita, debido a que el abaratamiento del trabajo es una exigencia del gran capital.

- Estigmatización de los inmigrantes como responsables de la crisis. En el contexto de la crisis general del capitalismo, la población migrante es señalada como culpable de la crisis, y surgen legislaciones y políticas de corte abiertamente represivo y antiinmigrante (Massey y Sánchez, 2010). Acontece una pérdida sensible de empleos, mientras que las condiciones de los que logran conservarse se deterioran y desembocan en deportaciones. El resultado visible es la drástica degradación del nivel de vida de los migrantes y sus dependientes económicos. Aunque, no prospera la expectativa de retornos masivos de migrantes y el desplome de los flujos de remesas, hay evidencias de que el flujo de nuevos migrantes laborales disminuye.

Las respuestas a la crisis orquestadas por gobiernos y organismos internacionales han sido cortoplacistas y excluyentes. En vez de atacar las causas de fondo de la problemática, promueven programas de rescate («salvataje») en beneficio de las grandes corporaciones financieras y manufactureras que afrontan problemas de bancarrota, lo cual incluye programas de flexibilización laboral, incremento de impuestos, ajustes al gasto social, entre otras disposiciones semejantes que pasan la factura a la clase trabajadora, amén de que se ha intensificado la sustracción de excedentes de la periferia para rehabilitar las finanzas corporativas de las matrices ubicadas en las grandes metrópolis. En definitiva, estas medidas no son más que tentativas desesperadas de prolongar los privilegios de las élites sin acometer las raíces de la profunda crisis en que está sumergido el capitalismo monopolista. 


\section{EPISTEMOLOGÍA DE LAS ALTERNATIVAS}

La construcción de alternativas sociales interpela dos consideraciones iniciales: la primera consiste en deconstruir el poder del capital y el Estado, un poder constituyente, estructural, que actúa como una fuerza hegemónica a la cual es necesario confrontar, pues no hacerlo nulifica cualquier pretensión de crear alternativas y justifica posturas ilusorias, ingenuas e irrelevantes; la segunda consideración consiste en detectar puntos de fisuras, fracturas o espacios a partir de los cuales los sectores sociales subalternos pueden generar alternativas sociales de desarrollo. Este desafío alimenta el debate entre quienes postulan la tentativa de cambio social sin tomar el poder o creando formas económicas no capitalistas dentro del capitalismo y quienes plantean la necesidad de un cambio de sistema para crear otra economía y otra sociedad. Sin profundizar en estos debates, en este momento solamente nos interesa destacar que, desde la perspectiva del sur, se está cuestionando el orden (o desorden) social vigente al caracterizarlo como un sistema injusto, inhumano y depredador, a la vez que se plantea la necesidad de construir alternativas de desarrollo social incluyentes.

Desde una perspectiva crítica que cuestiona la institucionalidad neoliberal y las dinámicas estructurales del capitalismo con miras a promover alternativas de desarrollo en beneficio de la mayoría de la población, el desarrollo humano sustentable se entiende como un proceso de construcción social que tiene como preámbulo la formación de conciencia de cambio y la organización y participación de la sociedad para formar un poder popular que busque la emancipación social, es decir, la supresión de relaciones sociales de alienación que demeritan a la persona humana, destruyen el medio ambiente y deterioran la convivencialidad.

Para caracterizar el desarrollo humano sustentable es menester desentrañar sus componentes esenciales. En primer término, tiene un carácter humano porque está centrado en la vida $\mathrm{y}$, por tanto, no puede sino concebirse en oposición a la centralidad del capital y su exigencia de la máxima ganancia posible. Este primer peldaño de su definición es necesario, aunque no es suficiente, porque puede quedarse postrado en un humanitarismo abstracto. La pretensión de un verdadero desarrollo 
humano implica consecuentar una condición social que permita la equidad y la justicia social en todos los planos y niveles sociales y espaciales. La sustentabilidad requiere, por su parte, que la estrategia de desarrollo sea factible, realista y perdurable, con un sólido basamento social, político, económico, cultural y ambiental. No obstante, el desarrollo humano no puede definirse ex ante, como un modelo de aplicación universal o como un diseño de gabinete, sino que requiere plantear y precisar las estrategias específicas, a partir de reconocer los obstáculos estructurales, las ataduras institucionales, las peculiaridades espaciales, las culturas regionales y las prácticas de los actores sociales.

\section{Redefinición del desarrollo humano}

El concepto dominante de desarrollo, emanado del pensamiento neoclásico y neoliberal, se constriñe al crecimiento económico, la competitividad y el libre mercado. El proceso de desarrollo se traza como una ruta por la cual los países que adoptan los programas de ajuste estructural, la economía de mercado y la democracia electoral podrán arribar al idílico primer mundo. No obstante, la evidencia empírica devela que los rasgos básicos del capitalismo contemporáneo se pueden sintetizar en la profundización de las asimetrías entre países y regiones, así como en la expansión e intensificación de las desigualdades sociales.

Frente a la ideología neoliberal y la evidencia de exclusión y despojo por doquier, nociones como desarrollo humano (Sen, 2000; PNUD, 2009) significan un avance notable. Sin embargo, resultan notoriamente insuficientes para entender y afrontar la complejidad de las nuevas dinámicas del desarrollo desigual, la migración forzada y la vulneración de los derechos humanos. Es imprescindible incorporar a esta vertiente de reflexión aspectos centrales de la cuestión del desarrollo: contextualizar la problemática, identificar los proyectos sociales en pugna, explorar la organización social autónoma y definir agendas alternativas de transformación social. Más que nunca, aflora la necesidad de repensar el desarrollo humano, no bajo la premisa de la libertad individual y el libre mercado, 
sino bajo el eje alterno de la igualdad, la justicia social y el bien común. ${ }^{11}$ A contracorriente del modelo regresivo de la globalización neoliberal, la perspectiva del sur propone un amplio abanico de estrategias y políticas de corte postneoliberal que el mainstream ha relegado, como en su momento lo hiciera con las teorías del estructuralismo y la dependencia.

El desarrollo humano puede definirse como un proceso de emancipación social encaminado a una transformación que posibilite a las clases sociales subalternas desprenderse de relaciones de explotación, opresión, despojo y discriminación. El proyecto de cambio social no tiene una sola ruta o respuesta, ni responde a un pensamiento iluminado. Incluso puede admitir expresiones alternativas al capitalismo aún dentro de la vigencia de la relación de capital como mecanismo dominante, pero no necesariamente absoluto y determinante de todas las formas de convivencia y socialización. Empero, se entiende que la expresión plena del desarrollo humano sustentable sólo se da con la superación de toda forma de explotación, desigualdad y subordinación entre los diversos sectores sociales y ámbitos territoriales.

En primer lugar, el desarrollo humano está orientado a generar condiciones de «buen vivir» para las clases, grupos y sectores subalternos, es decir, los pobres, excluidos y despojados, que conforman la mayoría de la población, en contraposición al interés supremo de maximizar las ganancias corporativas mediante estrategias que demeritan al grueso de la humanidad como un simple insumo productivo desechable.

El desarrollo humano significa la reconstrucción de la condición social de la humanidad en términos de dignidad, equidad, justicia social y bien común. Para configurar un «buen vivir», es necesario: 1) suprimir las relaciones de explotación, despojo, opresión, discriminación y

\footnotetext{
${ }^{11}$ Un gran problema que gravita en el debate es la frivolización del lenguaje que vacía de contenido los conceptos en boga, demerita el poder explicativo del conocimiento social y termina por deslindarse de la movilización social. El dilema se da entre redefinir los conceptos a la luz de la problemática concreta y la formulación de alternativas o emplear otras categorías. El primer camino tiene la gran desventaja de que lo gelatinoso de los términos anula indagaciones subsecuentes, y el segundo, que emplear vocablos nuevos nos coloca en un lugar inaccesible para la mayoría de los interlocutores. Ante esta disyuntiva, optamos por el primer camino. En términos metodológicos, es necesario emprender una operación de deconstrucción y reconstrucción crítica del concepto de desarrollo. Desde la perspectiva del sur puede articularse una visión histórica, estructural y estratégica.
} 
criminalización que padece la mayoría de la población; 2) desplegar las capacidades personales y sociales de producción, creación, crítica y participación; 3) garantizar la producción y reproducción de la vida humana en conjunción con el entorno planetario; 4) configurar un Estado social y una red de protección popular, y 5) reorientar los múltiples esfuerzos, energías y recursos públicos y sociales que generan excedente económico, conocimiento, bienes públicos y cultura para sostener la estrategia de desarrollo humano.

\section{CONCLUSIÓN}

A manera de conclusión, postulamos una serie de tesis para alentar el debate sobre la necesidad y posibilidad del desarrollo alternativo:

- El modelo de acumulación mundial y su sistema de poder no pueden ser desmantelados o reorientados sin la construcción de un poder social autónomo e independiente. Hoy por hoy, no existe un agente colectivo que confronte el poder inconmensurable que representa el gran capital, es decir, los grandes monopolios y oligopolios internacionales, los gobiernos y ejércitos imperiales, los organismos financieros internacionales y el entramado de actores asociados, que le dan soporte ideológico, diplomático y político. Existen, sin embargo, grandes esfuerzos locales, nacionales e internacionales para organizar grupos y movimientos sociales que defienden sus derechos ante la embestida neoliberal y que postulan algunas ideas y proyectos alternativos. La materialización de un proyecto alternativo al del gran capital, orientado al desarrollo humano, no provendrá «desde arriba», como consecuencia de la aplicación de las políticas del Consenso (o postconsenso) de Washington ni como concesión de programas que pretenden conferir un rostro humano al neoliberalismo, como las políticas de combate a la pobreza, la política de migración como palanca de desarrollo o los objetivos de desarrollo del milenio. Las estrategias de un verdadero desarrollo humano provendrán como resultado de procesos de construcción social que grupos organizados y movimientos de la sociedad civil, de la mano de la academia progresista, enarbolen en 
los planos local, nacional y, sobre todo, internacional. La configuración de un poder social contrahegemónico es una tarea impostergable que reclama la organización libre, autónoma e independiente de la sociedad civil, de la que han comenzado ya a darse avances importantes, como lo demuestran iniciativas emergidas desde el seno de la sociedad civil, por ejemplo, Vía Campesina, el Foro Social Mundial, el Foro de Acción Global de los Pueblos sobre Migración, Desarrollo y Derechos Humanos y el Foro Social Mundial de las Migraciones, entre otros.

- El Estado neoliberal funge como agente receptor y garante de la rentabilidad corporativa; en contraste, el Estado social es el agente promotor del desarrollo humano. El territorio, los recursos de la nación y la población se ofrecen como insumos baratos (competitivos, en la jerga neoliberal) para garantizar altos márgenes de ganancias, en tanto que las instituciones y políticas públicas actúan como garantes de las exigencias corporativas. Por tal razón, la reconstrucción del Estado es un requisito fundamental para activar dinámicas de desarrollo humano. Democratizar el acceso al poder a través de medios legítimos, legales y transparentes, así como promover una agenda parlamentaria y un marco jurídico vinculados a los intereses populares son pasos iniciales para armar la responsabilidad social del Estado como una red de protección social que garantice que los esfuerzos orientados a la generación de excedente desemboquen en mecanismos de redistribución bajo criterios de equidad. Desde el Estado social se puede refuncionalizar el papel de la economía campesina, la educación pública universal, el sistema de seguridad social, el acceso al empleo digno y la satisfacción de necesidades sociales como alimentación, educación y salud. El Estado social tiene la capacidad de establecer la responsabilidad social del poder y el capital y de proteger el trabajo y la naturaleza.

- La estrategia de expansión global del capital se fundamenta en el deterioro sistemático de las fuentes de riqueza, la población y la naturaleza, por lo que es indispensable reorientar los ejes de la acumulación cuyo eje toral de decisión sea la sustentabilidad social. Bajo el modelo actual, la fuerza de trabajo, al final de cuentas el único medio para que la mayoría de la población acceda a la subsistencia, se precariza al grado 
en que, para muchos trabajadores, el empleo es una fuente de pobreza e inseguridad; por su parta, la naturaleza representa un recurso o insumo productivo que se mercantiliza y sobreexplota a ultranza para garantizar una ventaja comparativa que luego redunde en ganancias extraordinarias bajo la forma de renta, sin importar sus costos sociales y ambientales. La noción de sustentabilidad social alude a la necesidad de garantizar la reproducción plena de la vida humana; esto no es posible sin asumir el reto de incentivar el metabolismo social, es decir, la simbiosis entre la población y la naturaleza, más allá de los afanes conservacionistas de ecologistas radicales. Asimismo, una estrategia de desarrollo humano sustentable requiere reorientar la gestión estatal del desarrollo para controlar la inversión extranjera, entablar tratados comerciales equitativos y complementarios, generar bases propias de desarrollo científico y tecnológico y, en general, combatir toda forma de intercambio desigual y transferencia de excedentes. Para que se dé un ejercicio soberano es necesario entablar nuevos esquemas de integración y cooperación regional.

- El desempleo estructural, la inseguridad laboral y la superexplotación atentan contra la dignidad y supervivencia de la mayoría de la población, por lo que es necesario generar formas de empleo digno, seguro y bien remunerado. Movido por la búsqueda compulsiva de ganancia, el capital privado recurre a programas de flexibilización, subcontratación y desempleo como estrategias para abaratar costos laborales; además, de manera tendencial, la innovación tecnológica convierte en prescindibles a un cúmulo de trabajadores. En el marcado laboral afloran categorías laborales sumamente precarias, como empleo informal, trabajador por cuenta propia y trabajo forzoso. En esta perspectiva, resulta crucial desmontar las estrategias de precarización e inseguridad laboral mediante la reivindicación de los derechos laborales, lo cual incluye el acceso al empleo digno, la restitución del sistema de seguridad social y la promoción del desarrollo humano, tanto en las periferias como en los centros del sistema mundial. Más aún, es imprescindible erigir la soberanía laboral, es decir, adoptar una política de Estado que persiga el objetivo de pleno empleo, no solamente con estrategias emergentes del Estado como empleador de última instancia o proveedor de seguro 
de desempleo, sino como gestor de mercados laborales que garanticen una dotación suficiente de empleo formal de calidad a la población en edad laboral, en particular en sectores estratégicos y necesarios para el desarrollo humano.

- La democracia de élites prevaleciente en los diversos ámbitos de poder debe ser reconvertida en una verdadera democracia, representativa y participativa. La democracia formal impuesta por el neoliberalismo, se reduce al plano electoral; el ciudadano, reducido a su mínima expresión, es convocado ritualmente a depositar un voto para elegir a personajes de la clase política, previamente seleccionados por las élites económicas y políticas, para que lo representen en los ámbitos del poder gubernamental o parlamentario. Promover la participación activa de la mayoría de la población en los asuntos públicos es un requisito insoslayable del desarrollo alternativo. Para ello se requiere, además de acceso a información fiable, generar espacios de deliberación y decisión pública, promover la organización y participación social, e impulsar instrumentos de participación propios de la democracia directa, tales como la revocación del mandato, la afirmativa ficta, el plebiscito, el referéndum y la iniciativa ciudadana.

- Ante el escenario sistémico de violencias estructurales e inseguridad humana, es menester defender los derechos humanos desde la sociedad civil y el Estado. Los derechos del capital campean abiertamente sobre los de la población, incluyendo los relativos a la preservación del medio ambiente. Un cambio radical en el sistema de valores es conceder primacía a los derechos humanos, en todos y cada uno de los capítulos económicos, laborales, sociales, políticos y culturales. Más aún, conviene postular el derecho al desarrollo humano para garantizar la satisfacción de las necesidades básicas, el acceso a un empleo digno, seguro y bien remunerado, y la posibilidad del despliegue de las capacidades críticas, creativas y artísticas de las personas y grupos sociales, además de la apertura de espacios para la participación en la toma de decisiones. La problemática de las migraciones forzadas, internas e internacionales, también requiere un tratamiento particular en materia de derechos para los migrantes y sus familias, en los ámbitos de origen, tránsito, destino, permanencia y retorno. En este sentido, el derecho a 
no emigrar es también un derecho al desarrollo en el lugar de origen, que implica la creación de bases materiales y subjetivas de arraigo de la población en un entorno de desarrollo humano generalizado, del bien común y de la supresión de los factores estructurales y políticos que catapultan la migración forzada. En contraposición a la libre movilidad del gran capital y las barreras a la movilidad de las personas, el derecho a la libre movilidad humana debe ser considerado como un atributo que aspira a la ciudadanía universal o, al menos, a ensanchar los ámbitos de libertad humana.

\section{BIBLIOGRAFÍA}

Amin, Samir (1971), Imperialismo y Comercio Internacional. El Intercambio Desigual, México, Siglo XXI.

Banco Mundial (2010), Migration and Remittances Factbook 2011, New York, Banco Mundial.

Bello, Walden (2006), "The Capitalist Conjuncture: Over-accumulation, Financial Crises, and the Threat From Globalisation», Third Word Quarterly, vol. 27, núm. 8, pp. 1345-1368.

BLACK, Richard (2001), «Environmental refugees: myth or reality?», New Issues in Refugee Research. Working Paper, núm. 34, Journal of Humanitarian Assistance. http://www.jha.ac/articles/u034.pdf, consultado el 5 de julio de 2010.

Bresser-Pereira, Luiz Carlos (2007), «Method and Pasion in Celso Furtado,» en E. Pérez y M. Vernego (eds.), Ideas, policies and economic development in the Americas, London, Routledge: 9-30.

Brewer, Anthony (1980), Marxist theories of imperialism, London, Routledge and Kegan Paul.

CASTLES, Stephen (2002), «Environmental change and forced migration: making sense of the debate», New Issues in Refugee Research. Working Paper, núm. 70, Refugees Studies Centre, University of Oxford.

(2003), «Towards a Sociology of Forced Migration and Social Transformation», Sociology, vol. 37, pp. 13-34.

Castles, Stephen y Raúl Delgado Wise (eds.) (2008), Migration and Development. Perspectives from the South, Genève.

Chatelain, Eugene (1979), «A qué conduce la tesis del intercambio desigual», Críticas de la economía política, núm. 10. 
Cypher, James y Raúl Delgado Wise, Mexico's Economic Dilemma. The Developmental Failure of Neoliberalism, Maryland, Rowman \& Littlefield.

Delgado Wise, Raúl y Humberto Márquez (2007a), «Teoría y práctica de la relación dialéctica entre desarrollo y migración», Migración y desarrollo, núm. 12.

(2007b), «The Reshaping of Mexican Labor Exports under nafta: Paradoxes and Challenges», International Migration Review, vol. 41, núm. 3, pp. 656-679.

(2009), «Understanding the Relationship between Migration and Development: Toward a New Theoretical Approach», Social Analysis, vol. 53, núm. 3, pp. 85-105.

Delgado Wise, Raúl, Humberto Márquez y Héctor Rodríguez (2009), «Seis tesis para desmitificar el nexo entre migración y desarrollo», Migración y Desarrollo, núm. 12, pp. 27-52.

Delgado Wise, Raúl, Humberto Márquez y Rubén Puentes (2010), «Elementos para replantear el debate sobre migración, desarrollo y derechos humanos», Acción Global de los Pueblos en Migración, Desarrollo y Derechos Humanos, Red Internacional de Migración y Desarrollo y Instituto de Estudios y Divulgación sobre Migración.

Emmanuel, Arghiri (1972), El intercambio desigual, México, Siglo XXI.

Florian, Patrik (1979), «Emmanuel con los filisteos», Críticas de la economía política, núm. 10.

FolAdori, Guillermo (2001), «El metabolismo con la naturaleza», Herramienta, núm. 16.

Foster, John Bellamy (1999), Marx's ecology. Materialism and nature, New York, Monthly Review Press.

Foster, John Bellamy y Fred Magdof (2009), The great financial crisis: causes and consequences, New York, Monthly Review Press.

Freeman, Richard (2005), «Does Globalization of the Scientific/Engineering Workforce Threaten U.S. Economic Leadership?», Working Paper 11457, National Bureau of Economic Research, http://www.nber.org/papers/w11457.

GzEsh, Susan (2008), «Una redefinición de la migración forzosa con base en los derechos humanos», Migración y Desarrollo, núm. 10, pp. 97-126.

Harvey, David (2007), "Neoliberalism as Creative Destruction», The Annals of the American Academy of Political and Social Science, núm. 610, pp. 21-44.

Hinkelammert, Franz y Henry Mora (2008), Hacia una economía para la vida. Preludio a una reconstrucción de la economía, San José de Costa Rica, Editorial Tecnológica de Costa Rica. 
Jolly, Susie (2005), Gender and Migration, Brighton, Bridge and Institute of Development Studies.

KAPUR, Devesh (2004), «Remittances: The new development mantra? G-24, Discussion paper series, núm. 29 (abril), Ginebra: unctAD, pp. 1-34.

Lester, Richard y Michael Piore (2004), Innovation-The Missing Dimension Cambridge, ma, Harvard University Press.

Lonergan, Steve y Ashok Swain (1999), «Environmental Degradation and Population Displacement», aviso, issue núm. 2. http://www.gechs.org/aviso/02/.

Mallorquín, Carlos (2007), «The unfamiliar Raúl Prebish», en E. Pérez y M. Vernego (eds.), Tdeas, policies and economic development in the America, London, Routledge, pp. 98-122.

Márquez, Humberto (2007), «Migración y desarrollo en México: entre la exportación de fuerza de trabajo y la dependencia de las remesas», Región y sociedad, vol. XIX, núm. 39.

(2009), «Diez rostros de la crisis civilizatoria del sistema capitalista mundial», Problemas del Desarrollo, vol. 40, núm. 159, pp. 191-210.

(2010a), «Crisis del sistema capitalismo mundial: paradojas y respuestas», Polis, vol. 9, núm. 27.

(2010b), «Desarrollo y migración: un lectura desde la economía política crítica», Migración y desarrollo, núm. 14.

(2010c), «La gran crisis del capitalismo neoliberal», Andamios, núm. 13 , pp. $57-84$.

Massey, Douglas y Magaly Sánchez (2010), Brokered Boundaries: Creating Immigrant Tdentity in Anti-Immigrant Times, New York, Russell Sage Foundation.

McAdam, Jane (ed.) (2010), Climate Change and Displacement: Multidisciplinary Perspectives, Oxford, Hart Publishing.

Munck, Ronaldo (2000), «Dependency and imperialism in Latin America, en R. Chicolte (ed.) The political economy of imperialism, Lanham, Md.: Rowmann\&Littlefield: 141156.

Myers, Norman y Jennifer Kent (1995), «Environmental Exodus: An Emergent Crisis in the Global Arena», Climate Institute, Washington.

Organización de las Naciones Unidas (onu) (2004), World Economic and Social Survey 2004, International Migration, New York.

(2006), «Seguimiento de la población mundial, con especial referencia a la migración internacional y el desarrollo», Informe del secretario general, e/cn.9/2006/3, 25 de enero.

(2010), Informe sobre desarrollo humano 2009. Superando barreras: movilidad y desarrollo humanos, New York. 
Organización Internacional del Trabajo (оIт) (2011), Tendencias mundiales del empleo 2011: el desafío de la recuperación del empleo, Ginebra.

Organización Internacional para las Migraciones (OIM) (2008), Informe sobre las migraciones en el mundo 2008. la gestión de la movilidad laboral en una economía mundial en plena evolución, Ginebra.

Osorio, Jaime (2010), «La exclusión desde la lógica del capital», Migración y desarrollo, núm. 14.

Prebisch, Raúl (1986), «El desarrollo económico en América Latina y alguno de sus principales problemas,» Desarrollo Económico, vol. 26, núm. 103 (editado originalmente en inglés en mayo de 1950).

Programa de las Naciones Unidas para el Desarrollo (PNUD) (1990), Informe sobre Desarrollo Humano 1990, Santa Fé de Bogotá: Tercer Mundo Editores.

Robinson, William (2008), Latin America and Global Capitalism: A Critical Globalization Perspective, Baltimore, Johns Hopkins University Press.

Schierup, Carl-Ulrik, Peo Hansen y Stephen Castles (2006), Migration, Citizenship, and the European Welfare State: A European Dilemma, London, Oxford University Press.

SEN, Amartya Kumar (2000), Desarrollo y libertad, Madrid, Planeta.

SнAікн, Anwar (1979), «Sobre las leyes del intercambio internacional», Críticas de la economía política, núm. 10.

Shuaizhang, F., A.B. Krueger y M. Oppenheimer (2010), «Linkages among climate change, crop yields and Mexico-US cross-border migration», pnas published ahead of print. http://www.pnas.org/content/early/2010/07/16/1002632107.full.pdf+html

SingA Boyenge, Jean-Pierre (2007) «ILO data base on export processing zones (Revised)», W.P.25, abril, Sectoral Activities Programme, Oficina Internacional del Trabajo, Ginebra.

Singer, Hans (1975), The Strategy of International Development. Essays in the Economics of Backwardness, London, Macmillan.

VAlenzuela, José (1979), «Emmanuel y el intercambio desigual», Críticas de la economía política, núm. 10.

VEGA, Renán (2006), «Imperialismo ecológico. El interminable saqueo de la naturaleza y de los parias del sur del mundo», Herramienta, núm. 31. 